\title{
MAXENT MODELLING FOR PREDICTING IMPACTS OF CLIMATE CHANGE ON THE POTENTIAL DISTRIBUTION OF ANABASIS APHYLLA IN NORTHWESTERN CHINA
}

\author{
Chang, Y. L. - XIA, Y. - Peng, M. W. - ChU, G. M. ${ }^{*}$ - Wang, M. ${ }^{*}$ \\ Department of Forestry, Agricultural College, Shihezi University \\ Road of North 4th, Shihezi City, Xinjiang 832003, China \\ *Corresponding authors \\ e-mail:chgmxj@163.com,wangm1205@163.com \\ (Received $4^{\text {th }}$ Oct 2019; accepted $8^{\text {th }}$ Jan 2020)
}

\begin{abstract}
Detailed and reliable information about the suitable distribution of species provides important knowledge for species protection management. The objectives of the study were to predict and analyze the potential distribution, driving factors and niche parameters of Anabasis aphylla under different scenarios. We combined the distribution data of A. aphylla, maximum entropy model and ArcGIS to predict the potential distribution of the plant in northwestern China under Paleoclimate, current and future (RCP4.5 2050 and RCP4.5 2070) climatic scenarios. The results showed the highly suitable distribution areas of $A$. aphylla were mainly concentrated in the southern margin of the Junggar Basin and the west side of the Tarim Basin. The primary environmental variable limit for the distribution of A. aphylla was precipitation seasonality. Precipitation and temperature have an important influence on the distribution of A. aphylla. According to the prediction of Palaeoclimate scenario, unsuitable areas of $A$. aphylla under the current, 2050 and 2070 climatic scenarios all increased, while the barely suitable areas of A. aphylla decreased. This study provides an important theoretical basis for the management, protection and restoration of A. aphylla.
\end{abstract}

Keywords: Anabasis aphylla, AUC, environmental variables, ecological niche, suitable area

\section{Introduction}

The study of the relationship between plant geographical distribution, climate and the prediction of plant spatial distribution pattern, is not only a research hots pot of traditional plant ecology and biogeography, but also an important research field of global ecology and global geography (Wang and $\mathrm{Ni}, 2009$ ). Climate change research has noted that due to the increasing of $\mathrm{CO}_{2}$ concentration in the earth's atmosphere, the global average temperature has increased over the past 100 years (Houghton et al., 2001). Climate change affected many ecosystems and biotas worldwide, it may accelerate the loss of biodiversity (Parmesan, 2006) and threaten the current distribution of species in the future (Araújo et al., 2011). In recent years, climate change and human activities have had a strong impact on the distribution of plant species in the arid northwest. Therefore, it is very necessary to study the future dynamics of vegetation in arid regions, which can provide better guidance for ecological protection and restoration in the arid regions of northwest China.

Anabasis aphylla is a chenopodiaceous shrub with high capabilities to endure salt-alkali, resist drought and prevent sand drift. It is also a constructive species for desert soil and plays a vital role in maintaining ecological stability and preventing natural disasters like desertification (Chu et al., 2014). Zhang et al. (2003) found that in areas with high groundwater level, easy to accumulate water and high salt content, $A$. aphylla occupied an absolute advantage. There were few studies on the correlation 
between the geographical distribution and environmental variables in a large area of $A$. aphylla. Jiang (2003) predicted the potential geographical distribution of Anabasis plants, and indicated that the distribution of Anabasis plants in China was concentrated in the arid regions of northwest. Based on 19 environmental variables and Maxent (maximum entropy model), Wang (2018) studied the distribution center of Anabasis plants in China, and found that these plants have higher adaptability to the arid and semi-arid climate than the warm temperate continental arid climate. All of these studies can provide a reference for the research in this paper. In china, A. aphylla is mainly distributed in northwest region, in diluvial fans, lowlands among dunes, in the Gobi desert and on hillsides (Chu et al., 2014). However, due to the influence of agricultural development, oil exploitation, harsh environmental conditions and other activities, the habitat of $A$. aphylla populations in Xinjiang was severely fragmented. All of this caused the self-renewal ability of $A$. aphylla population was poor, and most of the areas were in a recession trend (Chu et al., 2014). Therefore, it is of great practical significance for the management and protection of the plant to study the potential distribution range and spatial distribution pattern of $A$. aphylla under climate change scenarios.

In previous studies, Species Distribution Models (SDMs) have been used to model the potential geographic distribution of species in areas where the known distribution of species is lacking (Stockwell and Peters, 1999), and have also been used to estimate species distribution patterns and propose conservation strategies (Ortega-Huerta and Peterson, 2004). There are many different SDMs to choose from when predicting the potential distribution of species. This study selected the maximum entropy model (Maxent) as a predictive tool, as recent studies have shown that this method has a stronger ability to distinguish between the suitable and unsuitable regions of the species than other model methods (Phillips et al., 2006; Hernandez et al., 2008; Ma et al., 2017). Maxent has been demonstrated to be a powerful function when modelling rare species with narrow ranges and available scarce presence only occurrence data (Phillips et al., 2006; Elith et al., 2006, 2015; Pearson et al., 2007; Wisz et al., 2008; Rebelo and Jones, 2010; Sardà-Palomera et al., 2012; Garcia et al., 2013; Marcer et al., 2013). The advantages of Maxent including (1) the input species data can be presence only data; (2) both continuous and categorical data can be used as input variables; (3) its prediction accuracy is always stable and reliable, even with incomplete data, small sample sizes and gaps; (4) a spatially explicit habitat suitability map can be directly produced; and (5) the importance of individual environmental variables can be evaluated using a built in jackknife test (Yi et al., 2016). Studies using the Maxent model to predict the extent of species in different areas are concentrated on rare or endangered plants (Wilson et al., 2011; Babar et al., 2012; Marcer et al., 2013; Yi et al., 2016), invasive plants (Padalia et al., 2014) and insects (Santos et al., 2017; Wang et al., 2017). Maxent also has been successfully applied to the potential distribution of desert plant species in arid regions. Wang and Ni (2009) predicted the potential geographical distribution of five Caragana species in temperate arid and semi-arid regions of northern China. Ma et al. (2010) predicted the potential distribution and pattern of Gymnocarpos przewalskii in the desert area of Northwest China.

This study is based on the new scenario of the Fifth Interval Panel on Climate Change (IPCC): climatic factor data obtained from the RCP (Representative concentration pathways) 4.5 (medium emission scenario). Combined with the distribution data of A. aphylla, Maxent model and ArcGIS tools were used to predict the 
potential distribution, spatial pattern and changes of A. aphylla in northwestern China under Paleoclimate, current and future climatic scenarios. We aim to answer the following questions: (1) What is the distribution potential of A. aphylla in northwestern China under paleoclimate and current climate scenarios? (2) How will climate change affect the suitable distribution range and spatial pattern of A. aphylla in the future? (3) Which environmental factors and niche parameters that mainly restrict the distribution of $A$. aphylla?

\section{Materials}

\section{Study area}

In China, A. aphylla mainly distributed in the northwestern region. We attempted to find all possible habitats of A. aphylla in northwesten China, extending a certain distance to the surrounding area of the known geographical distribution of A. aphylla as the study area $\left(31^{\circ} 09^{\prime} \mathrm{N}-53^{\circ} 23^{\prime} \mathrm{N}\right.$ and $\left.73^{\circ} 40^{\prime} \mathrm{E}-126^{\circ} 04^{\prime} \mathrm{E}\right)$. The specific geographical scope of the administrative division of this area mainly includes the whole territory of Xinjiang, Inner Mongolia, Qinghai and Gansu. A geographic base map of China was obtained from the National Fundamental Geographic Information System (http://nfgis.nsdi. gov.cn). Most of the study area is arid and semi-arid and has a typical continental climate. The climate is dry all year with strong evaporation. Specifically, the dryness is greater than 4 (Ma et al., 2010), and the evaporation is basically more than $1000 \mathrm{~mm}$ (Wei et al., 2003). The study area is characterized by complex topography, fragile ecosystems, and long-term disturbance by human activities.

\section{Occurrence collection of A. aphylla}

The occurrence locations of $A$. aphylla were collected from databases, including the including the 1:1000000 vegetation atlas of China, the Chinese Virtual Herbarium dataset (CVH, http://www.cvh.org.cn/), Plant Photo Bank of China dataset (http://plantphoto.cn), Global Biodiversity Information Facility dataset (GBIF, https://www.gbif.org/) and some related references (Xu, 2003; Liu and Yang, 2006). Based on the occurrence location A. aphylla, we conducted extensive field investigations in Xinjiang, Badan Jaran Desert in Inner Mongolia and Jiuquan in Gansu during the summer (June to September) of 2017 and 2018. Xinjiang is the most distributed area of A. aphylla, the surveyed areas included Bole, Changji, Kashi, Atushi, Karamay and Shihezi. We found those areas where previously distributed with $A$. aphylla due to disturbances and disruptions of human activity are now less distributed, such as Karamay, Bole and Fukang of Changji. The distribution of A. aphylla in the core area was patchy. After removing repetitive occurrences and updating the distribution of $A$. aphylla, we obtained 99 data records for constructing the models. With the help of ArcGIS 10.4, a distribution of A. aphylla map was developed (Fig. 1).

\section{Environmental variables}

The 19 bioclimatic variables and one biophysical variable (altitude) with a 30s (ca. 1 $\mathrm{km})$ spatial resolution, downloaded from World Bioclimatic Database (http://www.worldclim.org). The current climate data (1961-1990) and Paleoclimate data for the Mid-Holocene (about 6000 years ago) were derived from CCSM4 (Collins et al., 2006). The future climate data for RCP4.5 for carbon dioxide for 2050 
(2041-2060 average climate) and 2070 (2061-2080 average climate) were included. Mid-Holocene is the most recent climate suitable period. Its radiation intensity and the increase of modern atmospheric $\mathrm{CO}_{2}$ have similar warming effects on the climate, so the Mid-Holocene climate simulation is of great significance for the prediction of climate scenarios for future global warming (Joussaume et al., 1995). This data set describes annual trends in climate, seasonality, and extreme environmental conditions and is often used for the prediction of niche models.

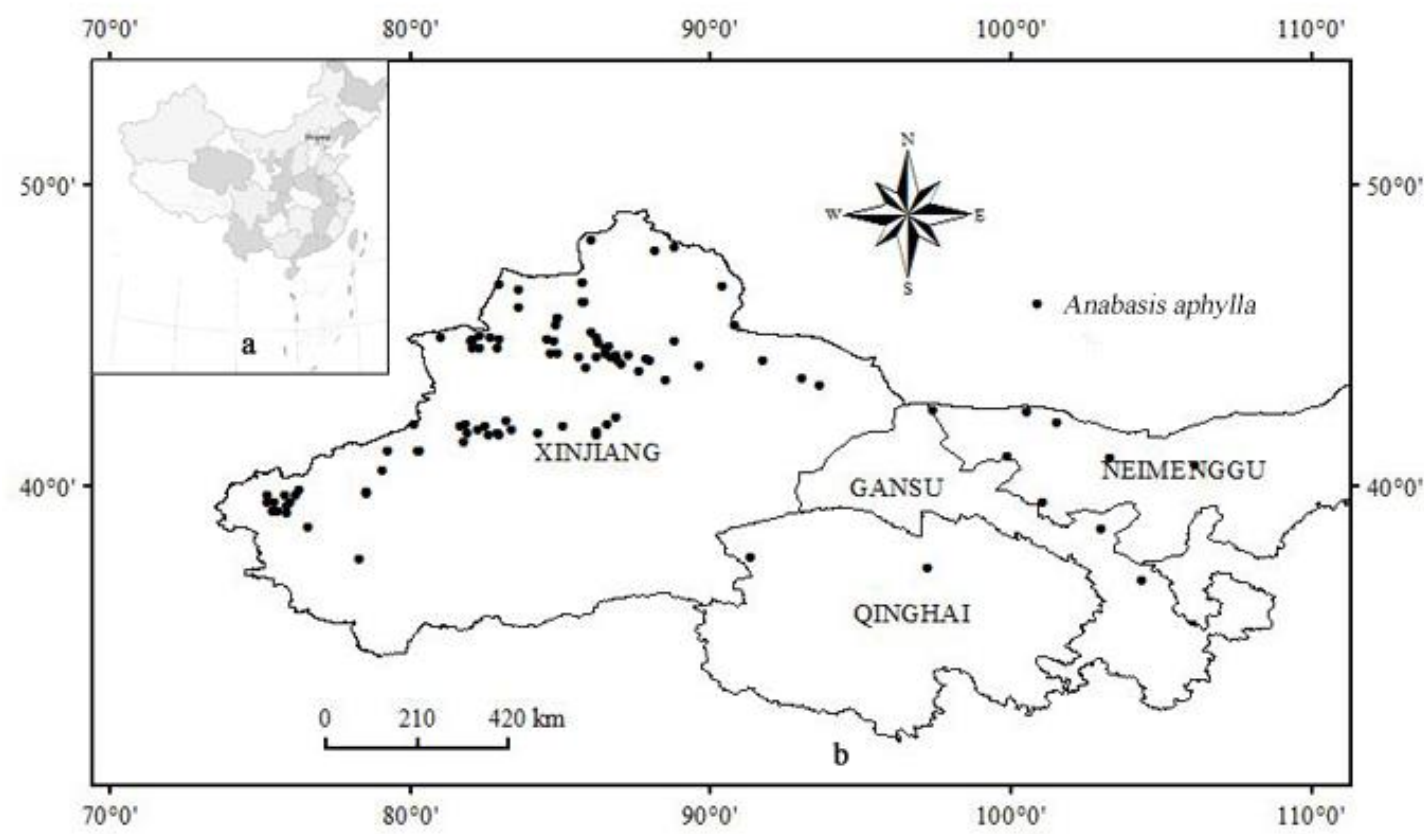

Figure 1. Distribution of A. aphylla used in this study (a) Map of China; (b) Distribution of A. aphylla in northwestern China

To avoid the collinearity between environmental variables, Maxent's jackknife was used to sort the 20 environmental variables according to their contribution rate. Environmental factors with a sum of 10 cumulative contribution rates $>90 \%$ were selected for models (Wei et al., 2019), including 9 bioclimatic variables and altitude data (Table 1). These variables included annual mean temperature (bio1), isothermality (bio3, Eq.1), minimum temperature of coldest month (bio6), temperature annual range (bio7, Eq.2), annual precipitation (bio12), precipitation of wettest month (bio13), precipitation of seasonality (bio15), precipitation of driest quarter (bio17), precipitation of warmest quarter (bio18) and altitude.

$$
\text { Isothermality }(\%)=(P 2 / P 7) \times 100
$$

Temperature Annual Range $\left({ }^{\circ} \mathrm{C}\right)=P 5-P 6$

where $\mathrm{P} 2$ is mean diurnal range; $\mathrm{P} 5$ is maximum temperature of warmest month; $\mathrm{P} 6$ is minimum temperature of coldest month; $\mathrm{P} 7$ is temperature annual range. 
Table 1. Environmental variables used in this study

\begin{tabular}{|c|c|c|c|}
\hline Environmental variables & Description & Unit & $\begin{array}{c}\begin{array}{c}\text { Contribution } \\
(\%)\end{array} \\
\end{array}$ \\
\hline Bio 1 & Annual Mean Temperature & ${ }^{\circ} \mathrm{C}$ & 8.8 \\
\hline Bio 2 & Mean Diurnal Range & ${ }^{\circ} \mathrm{C}$ & \\
\hline Bio 3 & Isothermality & - & 3.5 \\
\hline Bio 4 & Temperature Seasonality & $\mathrm{C}$ of $\mathrm{V}$ & \\
\hline Bio 5 & Maximum Temperature of Warmest Month & ${ }^{\circ} \mathrm{C}$ & \\
\hline Bio 6 & Minimum Temperature of Coldest Month & ${ }^{\circ} \mathrm{C}$ & 9.2 \\
\hline Bio 7 & Temperature Annual Range & ${ }^{\circ} \mathrm{C}$ & 4.9 \\
\hline Bio 8 & Mean Temperature of Wettest Quarter & ${ }^{\circ} \mathrm{C}$ & \\
\hline Bio 9 & Mean Temperature of Driest Quarter & ${ }^{\circ} \mathrm{C}$ & \\
\hline Bio 10 & Mean Temperature of Coldest Quarter & ${ }^{\circ} \mathrm{C}$ & \\
\hline Bio 11 & Mean Temperature of Coldest Quarter & ${ }^{\circ} \mathrm{C}$ & \\
\hline Bio 12 & Annual Precipitation & mm & 10 \\
\hline Bio 13 & Precipitation of Wettest Month & $\mathbf{m m}$ & 18.1 \\
\hline Bio 14 & Precipitation of Driest Month & $\mathrm{mm}$ & \\
\hline Bio 15 & Precipitation of Seasonality (Coefficient of Variation) & $\mathbf{C V}$ & 31 \\
\hline Bio 16 & Precipitation of Wettest Quarter & $\mathrm{mm}$ & \\
\hline Bio 17 & Precipitation of Driest Quarter & $\mathbf{m m}$ & 6.1 \\
\hline Bio 18 & Precipitation of Warmest Quarter & mm & 7.6 \\
\hline Bio 19 & Precipitation of Coldest Quarter & $\mathrm{mm}$ & \\
\hline Alt & Altitude & $\mathbf{m}$ & 0.9 \\
\hline
\end{tabular}

\section{Species distribution modelling}

This study used Maxent v3.3.3 software for analysis. We randomly selected $75 \%$ data for model training and $25 \%$ for model test. Selected the jackknife method in the environmental parameter settings, the remaining parameter settings selected the default parameters (Ma et al., 2017) and set 10 repetitions. The analysis results were output in logical format and ASCII type. For the 10 replicate results in different climate scenarios, used ArcGIS 10.4 to find the mean value as the final model result (Ma et al., 2017).

A Jackknife test was used to measure the variable importance in the model development, and receiver operating curve analysis (ROC) was used for model quality (Wang et al., 2017). The Jackknife test to examine the importance of individual variables for Maxent predictions. The receiver operating characteristic area under curve (AUC) method is a widely used procedure for comparing species distribution model performance of Maxent models (Lobo et al., 2010; Babar et al., 2012). The ROC plots the sensitivity values and the false positive fraction for all available probability thresholds (Manel et al., 2001). AUC provides a single measure of model performance independent of any particular choice of threshold. The AUC measures model performance ranging from 0 to 1 . Accuracy classification for AUC is: 1 $>$ excellent $>0.9>$ good $>0.8>$ fair $>0.7>$ poor $>0.6>$ fail (Swets, 1988).

For display and further analysis, we imported the results of the Maxent models predicting the presence of A. aphylla (0-1 range) into Arc GIS 10.4. Five classes of potential habitats were regrouped (Yang et al., 2013): unsuitable habitat (0-0.2); barely suitable habitat (0.2-0.4); suitable habitat (0.4-0.6); highly suitable habitat (0.6-0.7); very highly suitable habitat (0.7-1.0). For each model, we calculated the areas of $A$. aphylla under different climatic scenarios. 


\section{Results}

\section{Model performance and variables' contribution}

In this study, models predictive accuracy of A. aphylla habitat was assessed as a good level. Specifically, under the current and the RCP4.5 2050 period, the AUC values verified by the model results were 0.901. Under the Paleoclimate and the RCP4.5 2070 climate scenarios the value of AUC were 0.877 and 0.898 , respectively. This indicated that the potential growth area and ecological suitability of $A$. aphylla modelled by this study were highly accurate and reliable.

Under different climatic scenarios, the environmental variables that contributed most to the construction of the potential distribution model of A. aphylla with the Maxent algorithm were Bio15 (31\% of the variation), followed by bio13 (18.1\% of the variation), bio12 (10\% of the variation), bio6 (9.2\% of the variation), bio1 (8.8\% of the variation), bio18 (7.6\% of the variation), bio17 (6.1\% of the variation), bio7 (4.9\% of the variation), bio3 (3.5\% of the variation) and alt ( $0.9 \%$ of the variation) (Table 1, Fig. 2 ). The cumulative contributions of these factors reached values as high as $90.8 \%$. A. aphylla is highly adaptable to low temperature environments (Peng et al., 2018). Our previous studies showed that the seeds of $A$. aphylla can germinate in early spring when the ground is moist due to melting snow (Peng et al., 2018). In the Junggar Basin with more $A$. aphylla distributed, the annual extreme maximum temperature can reach $42.9^{\circ} \mathrm{C}$ (Chu et al., 2014). Therefore, A. aphylla has a strong adaptability to temperature.

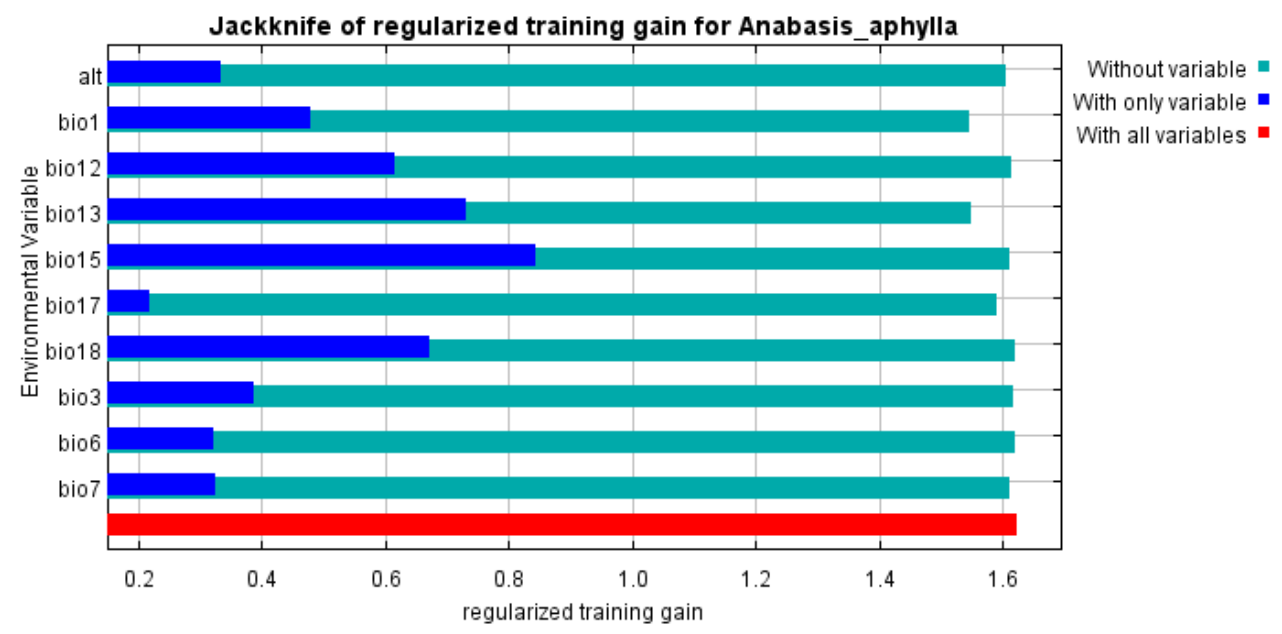

Figure 2. Results of the jackknife test of variables' contribution in modelling A. aphylla's habitat distribution (The regularized training gain describes how much better the Maxent distribution fits the occurrence data compared to a uniform distribution. The dark blue bars indicate the gain from using each variable in isolation, the light blue bars indicate the gain lost by removing the single variable from the full model, and the red bar indicates the gain using all of the variables)

\section{Response curves}

Response curves showed the quantitative relationship between environmental variables and the logistic probability of occurrence, which deepen our understanding of the ecological niche of species (Yi et al., 2016). This curves can provide useful 
information about the required environmental threshold (existence probability $>0.4$ ) for optimal growth of plant species. According to the response curve (Fig. 3), the probability of occurrence of $A$. aphylla decreases considerably in regions in which the precipitation of seasonality (bio15) is above $80 \%$ (Fig. 3A). The optimal growth annual precipitation of $A$. aphylla (bio12) was approximately $140 \mathrm{~mm}$ (Fig. 3B). The probability of occurrence of $A$. aphylla increases in areas with an annual mean temperature (bio1) between $5^{\circ} \mathrm{C}$ and $13^{\circ} \mathrm{C}$ (Fig. 3C).
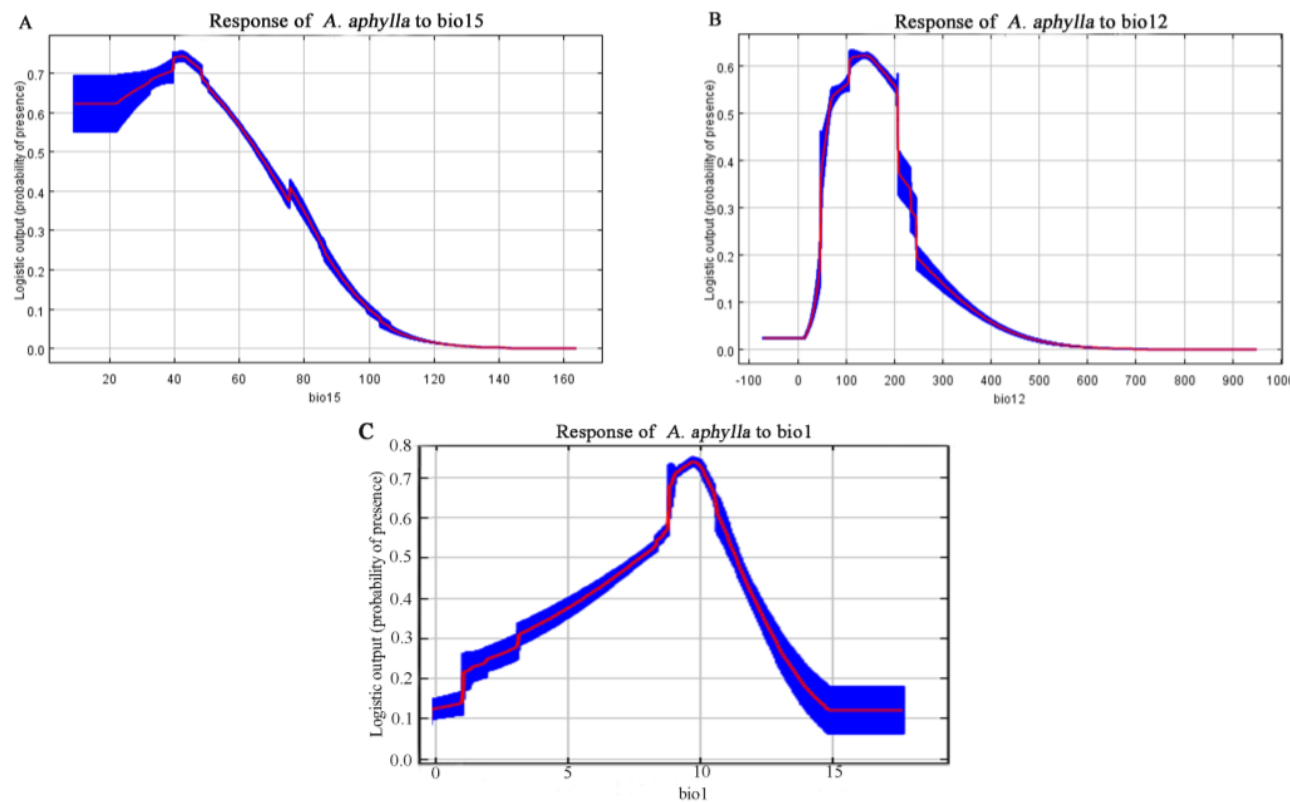

Figure 3. Response curves of the main environmental variables in A. aphylla's habitat distribution model (A) bio15: precipitation of seasonality (C of V); $(\boldsymbol{B})$ biol2: annual precipitation $(\mathrm{mm}) ;(\boldsymbol{C})$ biol: annual mean temperature $\left({ }^{\circ} \mathrm{C}\right)$

\section{Predicted geographical distribution of A. aphylla}

According to the predicted geographical distribution under different climatic scenarios (Fig. 4), the highly and very highly suitable distribution areas of A. aphylla were mainly concentrated in Xinjiang, of which the southern margin of the Junggar Basin and the western side of Tarim Basin were the very highly suitable areas. As far as the Xinjiang region was concerned, the distribution of $A$. aphylla in northern was more than in southern. In addition, A. aphylla also had a suitable distribution in some areas of the Hexi Corridor. The suitable distribution value of A. aphylla in Inner Mongolia and Qinghai was low. In Inner Mongolia, the expansion of the Badain Jaran Desert area may be one of the reasons for the reduced distribution area of A. aphylla. Compared with the Palaeoclimate scenario, the suitable areas of A. aphylla in the central part of Qinghai were reduced under the current and RCP4.5 2050 climatic scenarios.

According to the prediction of Palaeoclimate scenario, the total unsuitable areas of $A$. aphylla under the current, 2050 and 2070 climatic scenarios were increased, while the barely suitable areas of $A$. aphylla decreased (Table 2). The reduction of barely suitable area was mainly concentrated in central Inner Mongolia (Fig. 4). Compared with the current climate scenario, the very highly suitable distribution area of A. aphylla will decrease by $10.5 \%$ and $13.9 \%$ respectively in 2050 and 2070 (Table 2). 

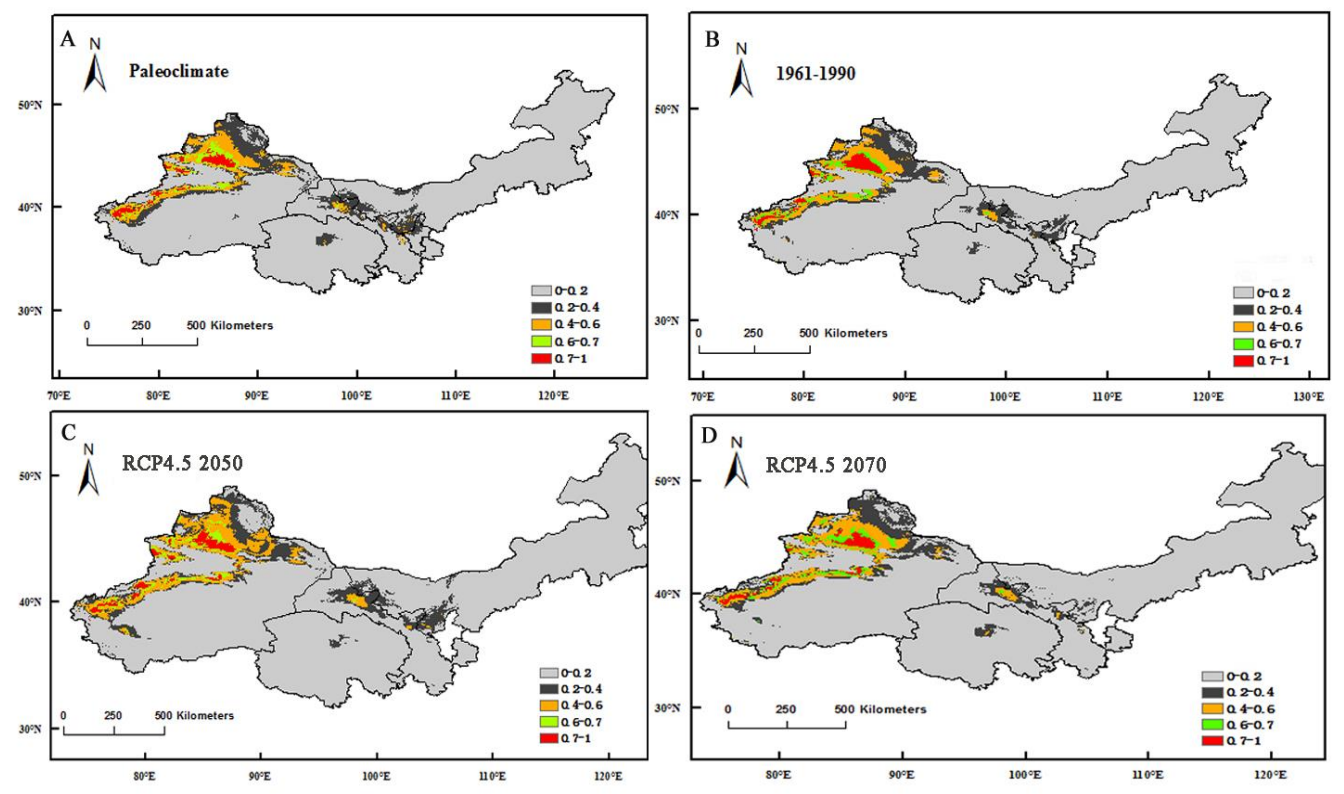

Figure 4. Predicted distribution of A. aphylla under different climatic scenarios $(\boldsymbol{A})$ under Paleoclimate scenario; (B) under current scenario; (C) under RCP4.5 2050 scenario; (D) under RCP4.5 2070 scenario

Table 2. Areas in unsuitable, barely suitable, suitable, highly suitable and very highly suitable of A. aphylla under different climatic scenarios

\begin{tabular}{c|c|c|c|c}
\hline Suitable grade & Palaeoclimate & $\mathbf{1 9 6 1 - 1 9 9 0}$ & $\mathbf{2 0 5 0}(\mathbf{R C P 4 . 5})$ & $\mathbf{2 0 7 0}(\mathbf{R C P 4 . 5})$ \\
\hline Very highly suitable & 5.7345 & 6.1109 & 5.4680 & 5.2587 \\
Highly suitable & 7.5168 & 6.3237 & 6.2516 & 6.9788 \\
Suitable & 20.0639 & 19.9467 & 21.6785 & 21.5845 \\
Barely suitable & 43.8072 & 35.7691 & 35.6073 & 34.3596 \\
Unsuitable & 345.7246 & 354.6966 & 353.8416 & 354.6654 \\
\hline
\end{tabular}

\section{Discussion}

Based on the Maxent model and GIS tools, this study predicted the potential distribution of $A$. aphylla in northwestern China under Paleoclimate, current and future climatic scenarios (Fig. 3). The A. aphylla's distribution points used for models were derived from the Chinese Plant Image Database, Vegetation Atlas, GBIF, CHV and published articles, these covered all distribution of A. aphylla in China. According to the ROC curve, the potential distribution model prediction results of $A$. aphylla during different climatic backgrounds showed that AUC values were higher than 0.877, indicating that the model prediction results were accurate and credible.

Under the Palaeoclimate and current climatic scenarios, the highly suitable distribution area of $A$. aphylla was mainly along the southern margin of the Junggar Basin and the west side of the Tarim Basin. In addition, the fitness value was higher in some areas of the Hexi Corridor, but low in most areas of Inner Mongolia and Qinghai. The highly suitable distribution area of $A$. aphylla found in this study was consistent with the findings of Wang et al. (2018). A. aphylla has a sporadic distribution in the Hexi Corridor area, and fragmentation is more serious. This finding may be related to the increase in evaporation caused by climatic warming in the Hexi Corridor, which has 
led to aggravation of drought in this part of the region and increased desertification trends (Ren and Yang, 2008). Under climatic scenarios in the future, the total suitable areas of $A$. aphylla will be increased. As the global climate continues to warm because of the increase in $\mathrm{CO}_{2}$, China's climate will accordingly change. According to the regional climatic model, annual precipitation in most parts of northwestern China will increase by more than $20 \%$ under a doubling of the $\mathrm{CO}_{2}$ concentration, with Xinjiang and Hexi increasing the most, reaching 20\%-50\% (Gao et al., 2001). Climate change has different effects on the distribution patterns of different species. Some species are threatened by climate change and are endangered or even extinct; others will benefit from climate change (Ma et al., 2017). In this study, it was determined that A. aphylla belongs to the latter case according to the change in its distribution area. At large spatial scales, climatic factors are key factors limiting the plant's potential distribution (Ma et al., 2017). However, in addition to the influence of abiotic factors on the distribution range of plants, human activities, interactions between species and the limitation of groundwater level all affect the geographical distribution pattern of species and their relationship with climate (Wang and $\mathrm{Ni}, 2009$ ).

The Maxent prediction results in this study showed that the suitable distribution area of $A$. aphylla was mainly along the southern margin of the Junggar Basin, the west side of the Tarim Basin and parts of the Hexi Corridor. A. aphylla often grows in gravel and saline soils in the desert at the front of diluvial fans, intermontane platforms and arid hillsides of low mountain (Chu et al., 2014); these areas were found to be more disturbed by human activities during the field investigation. Because of agricultural reclamation, oil exploitation and other human activities, the actual distribution of $A$. aphylla was mostly in patches with serious fragmentation. Particularly since the 1960s, the continuous increased population and the blind development of agricultural reclamation land resulted in a rapid expansion of desertification area. For example, along the southern margin of the Gurbantunggut Desert, the cultivated area increased from $818 \mathrm{~km}^{2}$ to $5500 \mathrm{~km}^{2}$, increasing the cultivated area nearly 7 times (Wei et al., 2003). Therefore, in view of the serious fragmentation caused by human activities, it is suggested to add $A$. aphylla to the list of endangered species for protection.

\section{Conclusions}

A. aphylla as one of the dominant species in the desert area of China, has strong drought tolerance. In this study, the highly and very highly suitable areas of A. aphylla were mainly concentrated in the southern margin of the Junggar Basin and the western side of Tarim Basin. The Maxent model's jackknife test of environmental variables showed that precipitation of seasonality $(31 \%)$ contributed most to the model. The models obtained in this study indicated that climate change had different effects on different suitable distribution areas. By calculating the area of the very highly suitable of A. aphylla, it will decrease in the future climate scenarios (Table 2). Therefore, by modelling the potential suitable area of $A$. aphylla and studying its niche requirements, it is of great significance for its protection in the future.

In this study, the potential distribution prediction of $A$. aphylla was only based on environmental variables, without considering the influence of human factors and ecological niche overlap between different species. In the actual distribution, A. aphylla was distributed in patches in the core area due to the influence of land use. Haloxylon ammodendron and other Anabasis plants have similar ecological characteristics to $A$. 
aphylla, so its geographical distribution is also affected by these plants. It is very necessary to study the geographical distribution of vegetation in combination with human disturbance and the overlap of niche between different species, so as to provide protection suggestions. Such as the establishment of core reserves. At the same time, $A$. aphylla is more affected by the topography in the distribution area. For example, it is separated by Tianshan mountain in Xinjiang and influenced by Hexi Corridor in Gansu. Due to the effects of reproductive isolation and environmental differences, genetic differentiation among populations of the same species distributed in different regions will occur (Guo, 2010). Therefore, it is of great significance to study the species evolution and genetic diversity of A. aphylla.

Acknowledgements. This work was supported by the Program of the National Natural Science Foundation of China (31460187), General Financial Grant of the China Postdoctoral Science Foundation (2017M613253) and Scientific Research Foundation of Shihezi University for Advanced Talents (RCZX201518, RCZX201521).

\section{REFERENCES}

[1] Araújo, M. B., Alagador, D., Cabeza, M., Thuiller, W. (2011): Climate change threatens European conservation areas. - Ecology letters 14: 484-492.

[2] Babar, S., Amarnath, G., Reddy, C. S., Jentsch, A., Sudhakar, S. (2012): Species distribution models: ecological explanation and prediction of an endemic and endangered plant species (Pterocarpus santalinus L.f.). - Current Science 102: 1157-1165.

[3] Chu, G. M., Wang, M., Zhang, S. X. (2014): Spatial point patters of Anabasis aphylla populations in the Proluvial Fan of South Junggar Basin. - Scientia Silvae Sinicae 50: 814.

[4] Collins, W. D., Bitz, C. M., Blackmon, M. L., Bonan, G. B., Bretherton, C. S., Carton, J. A., Chang, P., Doney, S. C., Hack, J. J., Henderson, T. B., Kiehl, J. T., Large, W. G., McKenna, D. S., Santer, B. D., Smith, R. D. (2006): The community climate system model version 3 (CCSM3). - J. Clim 19: 2122-2143.

[5] Santos, L. A. D., Mendes, M. F., Krüger, A. P., Blauth, M. L., Gottschalk, M. S., Garcia, F. R. M. (2017): Global potential distribution of Drosophila suzukii (Diptera, Drosophilidae). - Plos One 12: e0174318.

[6] Elith, J., Graham, C. H., Anderson, R. P., Dudik, M., Ferrier, S., Guisan, A., Hijmans, R. J., Huettmann, F., Leathwick, J. R., Lehmann, A. (2006): Novel methods improve prediction of species' distributions from occurrence data. - Ecography 29: 129-151.

[7] Elith, J., Phillips, S. J., Hastie, T., Dudík, M., Chee, Y. E., Yates, C. J. (2015): A statistical explanation of Maxent for ecologists. - Diversity and Distributions 17: 43-57.

[8] Gao, X. J., Zhao, Z. C., Ding, Y. H., Huang, R. H., Giorgi, F. (2001): Climate change due to greenhouse effects in China as simulated by regional climate model. - Advances in Atmospheric Sciences 18: 1224-1230.

[9] Garcia, K., Lasco, R., Ines, A., Lyon, B., Pulhin, F. (2013): Predicting geographic distribution and habitat suitability due to climate change of selected threatened forest tree species in the Philippines. - Applied Geography 44: 12-22.

[10] Guo, N. (2010): Genetic diversity of natural populations of Rosa Laxa Retz. and Rosa platyacantha Schrenk in Tianshan mountains of Xinjiang. - China Academy of Agricultural Science, Beijing, China.

[11] Hernandez, P. A., Franke, I., Herzog, S. K. (2008): Predicting species distributions in poorly studied landscapes. - Biodiversity and Conservation 17: 1353-1366. 
[12] Houghton, J. T., Ding, Y., Griggs, D. J., Noguer, M., Dai, X., Maskell, K., Johnson, C. A. (2001): Climate change 2001: the scientific basis. - Cambridge: Cambridge University Press.

[13] Jiang, X. (2003): Relationship between climate and geographic distribution of some plant species and prediction of species potential distribution in the arid land, northwest China. Chinese Academy of Science, Beijing, China.

[14] Joussaume, S., Taylor, K. E. (1995): Status of the Paleoclimate modeling intercomparison project (PMIP). - Proceedings of the First International AMIP Scientific Conference, WCRP Report. Monterey, California, USA 5: 425-430.

[15] Liu, X. C., Yang, Q. (2006): The Analysis on the Control Index of the Desert Vegetation in Dynamics and Restoring Strategy in Arid Area. - Research of Soil and Water Conservation 13: 99-103.

[16] Lobo, J. M., Alberto, J. V., Real, R. (2010): AUC: a misleading measure of the performance of predictive distribution models. - Global Ecology Biogeography 17: 145151.

[17] Ma, S. M., Zhang, M. L., Zhang, H. X., Meng, H. H., Chen, X. (2010): Predicting potential geographical distributions and patterns of the relic plant Gymnocarpos przewalskii using Maximum Entropy and Genetic Algorithm for rule-set prediction. Chinese Journal of Plant Ecology 34: 1327-1335.

[18] Ma, S. M., Wei, B., Li, X. C., Luo, C. H., Sun, F. F. (2017): The impacts of climate change on the potential distribution of Haloxylon ammodendron. - Chinese Journal of Ecology 36: 1243-1250.

[19] Manel, S., Williams, H. C., Ormerod, S. J. (2001): Evaluating presence-absence models in ecology: the need to account for prevalence. - Journal of Applied Ecology 38: 92-931.

[20] Marcer, A., Sáez, L., Molowny-Horas, R., Pons, X., Pino, J. (2013): Using species distribution modelling to disentangle realised versus potential distributions for rare species conservation. - Biological Conservation 166: 221-230.

[21] Ortega-Huerta, M. A., Peterson, A. T. (2004): Modelling Spatial Patterns of Biodiversity for Conservation Prioritization in North-Eastern Mexico. - Diversity \& Distributions 10: 39-54.

[22] Padalia, H., Srivastava, V., Kushwaha, S. P. S. (2014): Modeling potential invasion range of alien invasive species, Hyptis suaveolens (L.) Poit. in India: comparison of MaxEnt and GARP. - Ecological Informatics 22: 36-43.

[23] Parmesan, C. (2006): Ecological and evolutionary responses to recent climate change. Annual Review of Ecology. - Evolution and Systematics 37: 637-669.

[24] Pearson, R. G., Raxworthy, C. J., Nakamura, M., Peterson, A. T. (2007): Predicting species distributions from small numbers of occurrence records: a test case using cryptic geckos in Madagascar. - Journal of Biogeography 34: 102-117.

[25] Peng, M. W., Wang, M., Jiang, P., Chang, Y. L., Chu, G. M. (2018): The impact of low temperature on seed germination of two desert species in Junggar Basin of China. Applied ecology and environmental research 16: 5771-5780.

[26] Phillips, S. J., Anderson, R. P., Schapire, R. E. (2006): Maximum entropy modeling of species geographic distributions. - Ecological Modeling 190: 231-259.

[27] Rebelo, H., Jones, G. (2010): Ground validation of presence only modelling with rare species: a case study on barbastelles Barbastella barbastellus (Chiroptera: Vespertilionidae). - Journal of Applied Ecology 47: 410-420.

[28] Ren, Z. X., Yang, D. Y. (2008): Climate change and surface run off change impact on desertification in the arid area of northwest China in recent 50 years. - Journal of Arid Land Resources and Environment 22: 91-95.

[29] Sardà-Palomera, F., Brotons, L., Villero, D., Sierdsema, H., Newson, S. E., Jiguet, F. (2012): Mapping from heterogeneous biodiversity monitoring data sources. Biodiversity Conservation 21: 2927-2948. 
[30] Stockwell, D., Peters, D. (1999): The GARP modelling system: problems and solutions to automated spatial prediction. - International Journal of Geographical Information Science 13: 143-158.

[31] Swets, J. A. (1988): Measuring the accuracy of diagnostic systems. - Science 240: 12851293.

[32] Wang, J., Ni, J. (2009): Modelling the distribution of five Caragana species in temperate northern China. - Chinese Journal of Plant Ecology 33: 12-24.

[33] Wang, T. T., Chu, G. M., Jiang, P., Niu, P. X., Wang, M. (2017): Influences of Different Treatments on the Germination of Anabasis aphylla Seeds. - Journal of Northwest Forestry University 32: 125-129, 207.

[34] Wang, Y., Wen, Z. B., Zhang, H. X., Zhang, M. L. (2018): Geographical Distribution and Prediction on Potential Distribution Areas of Anabasis in China. - Journal of Desert Research 38: 1033-1039.

[35] Wei, W. S., He, Q., Liu, M. Z., Gao, W. D. (2003): Study on climate change and desert environment in Junggar Basin. - Journal of Desert Research 2(2): 101-105.

[36] Wei, W. S., He, Q., Liu, M. Z., Gao, W. D. (2003): Climate Change and the Desert Environment in Junggar Basin, Xinjiang, China. - Journal of Desert Research 23: 3-7.

[37] Wei, B., Ma, S. M., Song, J., He, L. Y., Li, X. C. (2019): Prediction of the potential distribution and ecological suitability of Fritillaria walujewii. - Acta Ecologica Sinica 39: 228-234.

[38] Wilson, C. D., Roberts, D., Reid, N. (2011): Applying species distribution modelling to identify areas of high conservation value for endangered species: a case study using Margaritifera margaritifera (L.). - Biol. Cons 144: 821-829.

[39] Wisz, M. S., Hijmans, R. J., Li, J., Peterson, A. T., Graham, C. H., Guisan, A. (2008): Effects of sample size on the performance of species distribution models. - Diversity Distribution 14: 763-773.

[40] Xu, L. (2003): Studies on ecological genetics of the important desert plants natural populations in Fukang, Xinjiang. - Northwest University, Shanxi, China.

[41] Yang, X. Q., Kushwaha, S. P. S., Saran, S., Xu, J., Roy, P. S. (2013): Maxent modeling for predicting the potential distribution of medicinal plant, Justicia adhatoda L. in Lesser Himalayan foothills. - Ecological Engineering 51: 83-87.

[42] Yi, Y. J., Cheng, X., Yang, Z. F., Zhang, S. H. (2016): Maxent modeling for predicting the potential distribution of endangered medicinal plant ( $H$. riparia Lour) in Yunnan, China. - Ecological Engineering 92: 260-269.

[43] Zhang, L. J., Yue, M., Zhang, Y. D., Gu, X. F., Pan, X. L., Zhao, G. F. (2003): Characteristics of plant community species diversity of oasis desert ecotone in Fukang, Xinjiang. - Scientia Geographica Sinica 23(3): 229-333. 